\title{
Bedeutung von § 9 S. 2 Nr. 3 PatG
}

§ 9 S. 2 Nr. 3 PatG ist auf Verwendungspatente nicht anwendbar. ${ }^{1}$ Im Rahmen der neuen Wirkungen bei bereits bekannter Verwendung gilt nichts anderes. Das Erforschen einer neuen Wirkung einer bereits im Stand der Technik bekannten Sache oder eines solchen Stoffes begründet kein Verwendungserzeugnis, das separat geschützt werden könnte. Insbesondere kann nicht die Sache oder der Stoff mit der neuen Wirkung gegenüber der Sache oder dem Stoff mit der alten Wirkung als ein neues Verwendungserzeugnis angesehen werden, das durch den Einsatz der Sache oder des Stoffes hergestellt worden ist. Auch ein Schutz der sinnfällig hergerichteten Sache oder des sinnfällig hergerichteten Stoffes kann nicht über § 9 S. 2 Nr. 3 PatG erreicht werden, sondern ist bereits durch den weiten Verwendungsbegriff erzielt worden. Somit ist $\S 9$ S. 2 Nr. 3 PatG für den Verbotsumfang der Fallgruppe der neuen Wirkungen bei bereits bekannter Verwendung nicht von Bedeutung.

${ }^{1}$ Vgl. dazu Teil II 5.2.2.2.2.2.

(C) Der/die Autor(en), exklusiv lizenziert durch Springer Fachmedien 